\title{
Construindo um novo espaço imaginário da publicidade na virada do século
}

\author{
Maria Helena Steffens de Castro ${ }^{1}$ \\ Doutora em Letras pela Pontifícia Universidade Católica do Rio Grande do Sul - PUC-RS, \\ onde é professora do Curso de Comunicaşão Social e do Programa de Pós-Graduação \\ da Faculdade de Comunicação Social nas Disciplinas de Métodos de Pesquisa em \\ Comunicação e Comunicação e Configurações Discursivas nas Instituições. \\ E-mail: mariahs@terra.com.br.
}

Resumo: $\mathrm{O}$ artigo propõe uma reflexão sobre o uso de documentos que fazem parte de acervos para a confecção de trabalhos de pesquisa acadêmica. Tanto as instituições mantenedoras quanto seus usuários têm consciência da importância desses documentos para a revisão da história no campo da comunicação e da educação. Os dados pesquisados colaboram para a formação de um leitor crítico, capaz de relacionar a publicidade como meio de fixar conhecimento em diversas áreas da sociedade.

Palavras-chave: comunicação, educação, publicidade, acervo, história.
Abstract: The article proposes a reflection to the use of documents of public or particular collections to make academic research works. The lowner institutions and the users manifest conscience of the importance of those documents for the revision of the history in the field of communication and education. The researched data indicate the formation of a critical reader, that it is capable to relate the publicity as fixer of knowledge in several areas of the society.

Keywords: communication, education, publicity, documents collection, history.

O levantamento e a recuperação das fontes da comunicação sul-rio-grandense fazem parte de um dos objetivos do Núcleo de Pesquisas em Ciências da Comunicação (NUPECG), ligado à Faculdade de Comunicação Social da Pontifícia Universidade Católica do Rio Grande do Sul. Sua finalidade é organizar, catalogar e divulgar espólios doados às universidades por comunicadores representativos do cenário gaúcho, com vistas a incentivar a criação de grupos integrados de pesquisa, através da consulta aos dados catalogados e colocados via internet, para trabalhos acadêmicos de alunos, jornalistas, pesquisadores e comunidade em geral.

Tais arquivos são marcas de indivíduos, grupos, instituições e governos, que retratam informações de valor permanente, como decretos, fotografias,

Recebido: 22.06 .2007

Aprovado: 04.01 .2008

1. Disponível em: $<$ http://lattes.cnpq. $\mathrm{br} / 8392548380032210>$. 
2. MORIN, Edgar. O método IV - as ideias. Portugal: Europa-América, 1991. p. 93. filmes, vídeos, gravações sonoras, coleções de jornais, revistas, além de documentos pessoais como cartas, diários e outros manuscritos, que necessitam de um método idôneo para serem selecionados, tombados, catalogados e colocados à disposição das pessoas interessadas, permitindo uma visão sinótica e detalhada da sua quantidade e natureza.

Neste artigo, mostrado como um catálogo informatizado, pode-se, a partir da seleção de campos específicos, recuperar informações importantes da propaganda que começa a profissionalizar-se, reconstituindo imagens perdidas de uma cidade e dando uma nova visão aos acontecimentos ou mesmo às tendências evolutivas marcantes desta história.

A escolha deste trabalho recaiu sobre a recuperação dos anúncios da Revista do Globo - RG, por ter sido o periódico mais importante do Rio Grande do Sul, editado em Porto Alegre. A decisão de catalogar o período compreendido entre 1929 e 1949 decorre do fato de esta ser a fase amadora e romântica da propaganda gaúcha. Foram catalogados 25.792 anúncios através do programa Win Isis, da Unesco. Trata-se de um software gerenciador de bancos de dados empregado na informatização de bibliotecas. Foram pesquisados 25 campos específicos da propaganda, compreendidos sempre como um conjunto da comunicação organizacional que tem como fim a divulgação de produtos que se apresentam diante de um novo cenário, para informar suas características a um consumidor que já vive transformações econômicas, advindas do processo de mudanças do País. A pertinência dos critérios estabelecidos para a definição e preenchimento dos campos foi possível com a consulta a vários profissionais da área de publicidade gaúcha, que muito auxiliaram na relação entre a história da propaganda e os anúncios catalogados.

$\mathrm{O}$ objetivo desta pesquisa foi oferecer um produto que promovesse e facilitasse outros estudos em diferentes áreas do conhecimento, a partir do catálogo existente e pelo contingente de informações importantes que surgiram sobre medicamentos, alimentos, vestuário, higiene, turismo, arquitetura, espetáculos de cultura, esporte e outros, uma vez que tais produtos estabeleciam complexas relações entre si e a sociedade que os utilizava. Assim, procurou-se incentivar a reflexão crítica entre as contradições e as mediações que a história retrata, reconstituindo-se uma parte do todo social, que aponta para um contexto comum de uma determinada época, em que o importante era a "inadequação entre a coerência interna de um sistema de ideias aparentemente racional e a realidade à qual ele se aplicava" ${ }^{2}$. O resultado deste trabalho pode ser encontrado na coleção de CDs produzida pelo Curso de Letras da PUC-RS e enviada a todas as bibliotecas universitárias do País.

\section{O UNIVERSO DA PRODUÇÃO DE MASSA}

No início do século XX apareceram excelentes revistas literárias no Brasil, e a comunidade rio-grandense ressentia-se da falta de um veículo 
de divulgação de suas atividades culturais. José Bertaso, sensível ao apelo de amigos que ocupavam o Governo do Estado, entre eles Getúlio Vargas, fundou, então, a Revista do Globo, que circulou de 1929 a 1967, tornando-a vitrine da tradicional livraria da rua da Praia e de sua editora, em Porto Alegre-RS. Destacado grupo de intelectuais e de artistas plásticos já conceituados fez parte do corpo redacional, ilustrando as capas, os contos de escritores, e também criando alguns reclames, considerados, então, uma arte menor, já que envolvia a venda de produtos.

A edição e a divulgação do catálogo sobre a propaganda abriram um universo de informações dos quase quarenta anos da Revista - até então, praticamente vedado aos alunos e pesquisadores -, determinando o aumento de consulentes, pois cada anúncio catalogado tornava-se um documento, lançado sobre um olhar interrogativo que buscava reconstituir as contribuições históricas, culturais, políticas e educacionais da publicidade gaúcha, as quais se encontram de tal modo articuladas, que são difíceis de ser discutidas separadamente.

Cultura, neste artigo, é trabalhada no sentido do que é exclusivo, de fruição apenas pelos que estão no topo da pirâmide, separada do povo como polos distintos. Analisadas através de uma pedagogia construtivista, tais peças publicitárias revelavam a cultura como processo dinâmico, pois, segundo Becker, "dos escombros do passado, delineia-se o horizonte do futuro; organizando o significado que dá plenitude ao presente"3. Essa orientação pressupõe um conceito de educação com base em um contexto complexo e no desenvolvimento de um pensamento crítico; é estudar a propaganda e seus criadores, sua recepção na época, enfim, sua comunicação com outros setores no decorrer da história e seu potencial transformador da sociedade.

Por isso, a pesquisa em periódicos tem um amplo campo de atuação, quando propõe não somente uma nova forma de utilização dos bens culturais do passado, como, também, uma nova postura por parte do receptor, no sentido de incorporá-la ao processo de construção e transformação do conhecimento. Como diz Gomes, "a reflexão implica a inversão constante do homem no mundo de sua experiência, num mundo carregado de conotações, valores, intercâmbios simbólicos, correspondências afetivas, interesses sociais e cenários políticos”, levando-o a participar de uma paisagem com novas frentes de avanço, que na época buscavam a identificação e a humanização do mundo da produção em massa.

\section{CONSTRUINDO O ESPAÇO PUBLICITÁRIO}

Concluída a catalogação, verificou-se que, nos vinte primeiros anos de publicidade na revista, foram veiculados 25.792 anúncios, muito repetidos ao longo do tempo, uma vez que ainda não existia tanta concorrência no mercado. Feita a eliminação das cópias coincidentes, o corpus passou a ser constituído, então, por 7.069 anúncios inéditos.
3. BECKER, Fernando. Modelos pedagógicos e modelos epistemológicos. Educação e realidade. Petrópolis: Vozes, 1993. p. 94

4. GOMES, Angel Perez. O pensamento prático do professor: a formação do professor como profissional reflexivo. In: NÓVOA Antonio. Os problemas e sua formação. Lisboa: Dom Quixote, 1992. 


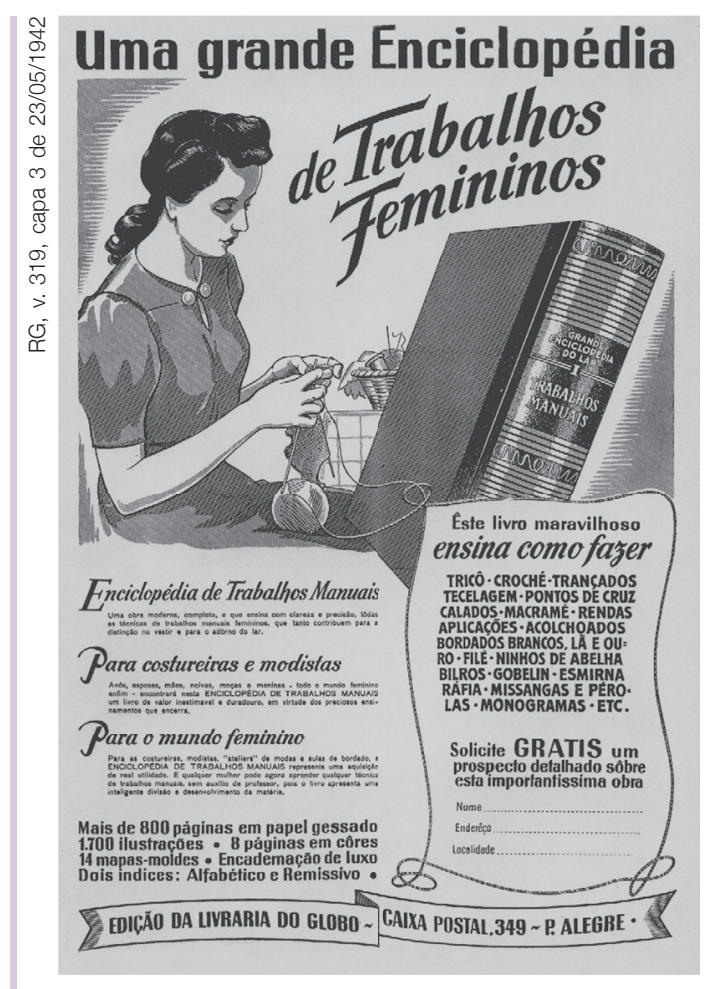
para diferentes gêneros de produtos, incentivando o consumidor à ação de compra, com apelos sedutores.

Segundo Cobra ${ }^{5}$, em publicidade denomina-se gênero o conjunto de objetos que apresentam certo número de características comuns quanto ao seu uso, convencionalmente estabelecidas pelo comércio e aceitas pelo mercado publicitário. No período analisado, foram selecionados trinta e dois gêneros de produtos ou serviços, de acordo com algumas classificações a seguir: alimento/bebida; beleza; construção; cultura; decoração; eletrodomésticos; ensino; higiene; saúde; vestuário; escritório; meios de comunicação social; esporte; esoterismo e outros com um número menor de inserções.

Com os dados catalogados e cruzados com outros campos, no final do trabalho foi possível reconstituir aspectos importantes da história de Porto Alegre, no início do século, tais como:

Definidos os critérios e bases para a indexação dos anúncios, iniciaram-se as atividades de coleta dos dados, criando campos específicos para os de cunho publicitário, tais como: marca do produto; tipo de ilustração e de texto; logotipo; agência de publicidade; ocorrência sazonal ou campanha; dimensões do anúncio; slogan; gênero do produto; público-alvo; tipo de apelo empregado. Tais campos apresentavam largas possibilidades combinatórias para gerar informações mais completas e específicas, segundo diferentes áreas de conhecimento, pois possibilitavam cruzamentos de informações que iam delineando o contexto cultural e social de uma Porto Alegre que rompia limites e ampliava mercados
5. COBRA, Marcos. O impacto da propaganda: um estudo para algumas classes de bens. São Paulo: Atlas, 1991.

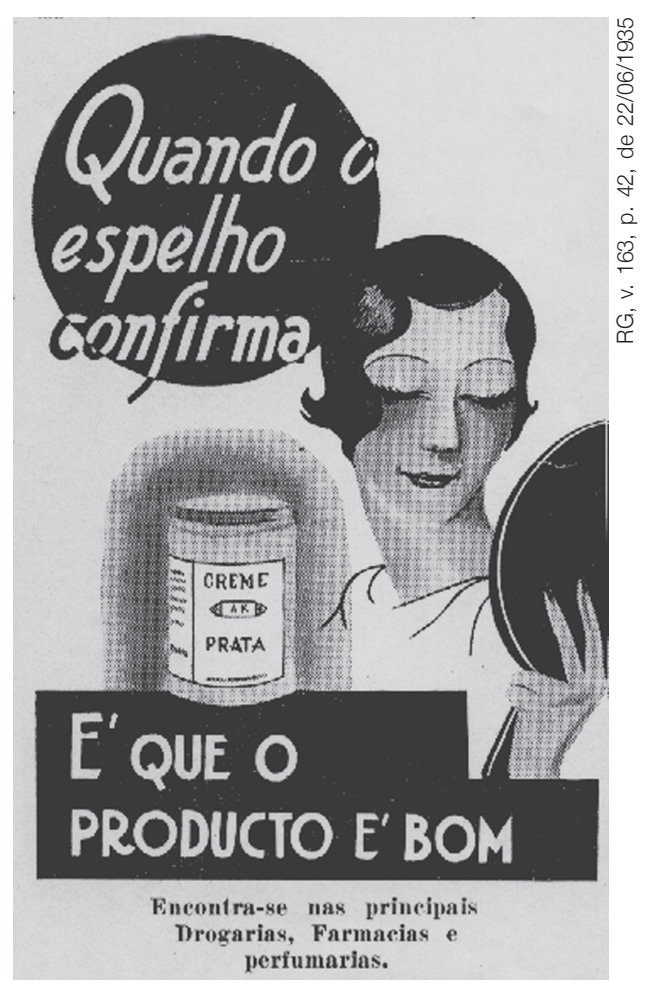


Gênero - Ensino: anúncios que envolvem ofertas de serviços instrucionais e musicais. Ao longo da pesquisa apareceram 258 exemplos, sendo 62 inéditos, de profissionais oferecendo aulas de piano, canto, língua francesa etc., como clientes sazonais ou temporários. Também modistas ofereciam aulas de corte e costura, bordados feitos à máquina ou à mão etc. Apesar de Porto Alegre possuir, na década de 1940, várias escolas de ensino secundário, cinco ginásios masculinos, três femininos e três mistos, não era costume anunciar seus serviços pela imprensa. Em $1939^{6}$ havia 366.712 alunos matriculados nas escolas, sendo 110.596 na rede estadual, 137.844 na rede municipal e 118.272 nas escolas particulares.

Gênero - Entretenimento: publicidade sobre casas de espetáculo e lazer, bem como de festas e reuniões dançantes. Dos 24 anúncios catalogados, 19 são inéditos, representando clientes fixos, como Cassino Farroupilha e Bingo Frontão Gaúcho, que divulgaram suas festas por mais de um ano. Outro cliente assíduo era o Rink Club, centro esportivo de patinação, esporte muito praticado pelos jovens da época. As sociedades esportivas que ofereciam futebol, remo, natação, polo, basquete etc. constituíam os divertimentos populares por excelência e "raro é não estarem os estádios e pavilhões repletos de povo, sempre que haja qualquer competição"7.

Gênero - Alimento e bebida: anúncios de farináceos, conservas, bebidas alcoólicas ou não, bem como condimentos usados na preparação de alimentos. Foram catalogados 1.799 anúncios, sendo 518 inéditos. Maizena Duryea foi anunciante por dezessete anos e onze meses; os produtos da marca Peixe apareceram por treze anos e dois meses, seguidos do Fermento Royal, veiculado por onze anos e três meses. A Cervejaria Continental anunciava com frequência, e na inauguração da máquina de impressão litográfica, adquirida pela Livraria do Globo em 1938, foram impressos milhares de rótulos da empresa, como ato simbólico pela aquisição da impressora. Também essa empresa é capa da RG, num belo trabalho alusivo ao Natal, realizado por Nelson Boeira Faedrich ${ }^{8}$, onde aparecem os três reis magos oferecendo a Cerveja Continental como presente a Jesus. Essa empresa foi adquirida pela Cervejaria Brahma, que publicou seu primeiro anúncio na RG em 8 de maio de 1948.

Gênero - Autopromoção: anúncios da própria RG. Ao todo foram catalogados 199 deles, com 70 inéditos. Buscavam motivar o leitor para a assinatura da revista ou divulgavam uma nova fase ocasionada por mudanças na diretoria e avanços tecnológicos. Em 1933, sob a direção de Érico Veríssimo, a RG anuncia sua primeira mudança, para torná-la "um dos magazines melhores e mais modernos do Brasil, publicando literatura, ciência, cinema, rádio e televisão, história, seção feminina e infantil, poesia, arte, enxadrismo, humorismo, reportagens, esporte e contos" ${ }^{9}$.

Gênero - Beleza: oferta de cosméticos, produtos de maquiagem e perfumes. No período analisado foram catalogados 4.261 anúncios, sendo 1.042 inéditos. Os anunciantes mais assíduos foram Juventude Alexandre,
6. REVISTA DO GLOBO. Porto Alegre: Livraria do Globo, n. 285 , p. 124,30 nov. 1940.

7. PEREZ, J. T. (Org.). Porto Alegre por dentro e por fora. Visão Panorâmica da capital do Estado do Rio Grande do Sul: sua vida e potencial econômico; retrato da cidade de Porto Alegre. Porto Alegre: Continente, [s.d.].

8. REVISTA DO GLOBO, Porto Alegre: Livraria do Globo, n. 174, dez. 1935 capa I.

9. Ibid., n. 105, $18 \mathrm{fev}$. 1933, capa IV. 
uma tintura para cabelo, que veiculou por dezenove anos e nove meses o mesmo anúncio, e Creme Brancol, que apareceu por dezoito anos e nove meses. Esses anúncios foram realizados pela agência Star. Outro produto, a Cera Mercolized, orientou, por dezessete anos e seis meses, as mulheres como passá-la no rosto para renovar as células da pele.

Nos primeiros anos da RG,

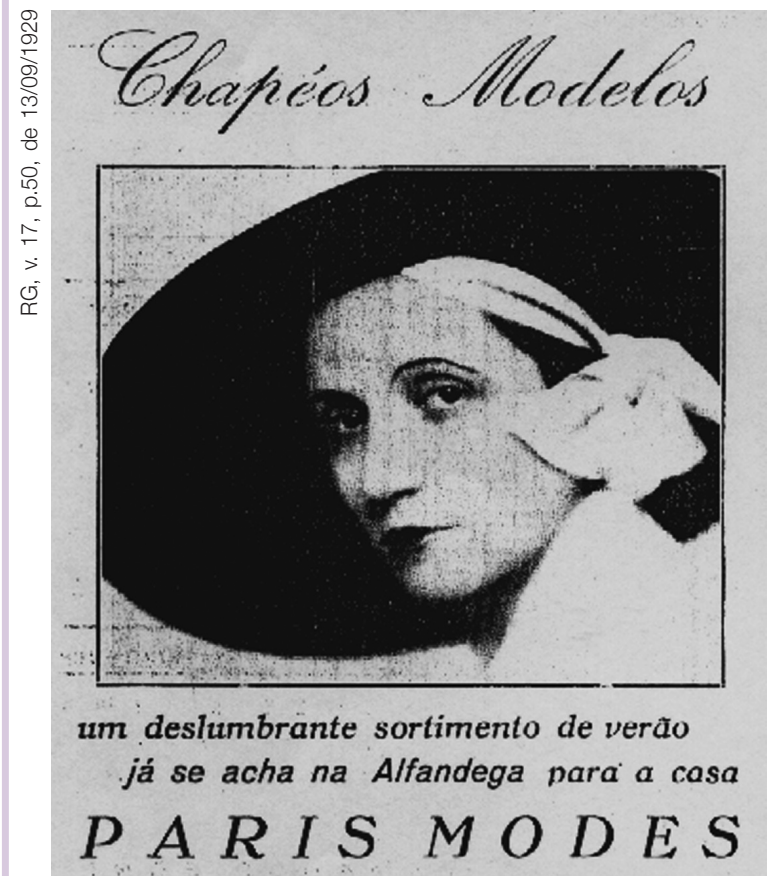
a imagem da mulher era representada através de desenhos manuais, como uma pessoa meiga, gentil, identificada com a boa mãe e a dona de casa. A sensualidade do corpo exposto não era explorada, porque eram pagos altíssimos cachês para fotos que exibissem partes do corpo feminino não mostradas habitualmente.

O culto ao belo era muito divulgado, pois cabia à mulher "cuidar da higiene para conservar a frescura da pele e a elasticidade dos músculos, o cuidar dos dentes, das unhas, dos cabelos de tal maneira que a fealdade não tenha aonde se esconder"10. A publicidade, então, é pródiga em anúncios de produtos de beleza como Baton Michel, Royal Briar, Dagelle, Baton Tangee, Creme Rugol e Stacomb, anunciados por mais de dez anos. A Casa Coelho era um estabelecimento comercial especializado em produtos de beleza e anunciou por treze anos e nove meses na RG.

Os produtos de maquiagem dividem o espaço no campo beleza com grandes empresas, que prometem a eterna juventude e relacionam o produto à personalidade da mulher: "A mulher inteligente escolhe um rouge fino que convenha à cor de sua cútis, propaga a linha de produtos da Royal Briar"11.

Gênero - Cultura: anúncios de livros, exposições de arte, filmes e peças teatrais. Neste campo foram catalogados ao todo 542 exemplos, com 300 inéditos. O item livros foi o predominante, uma vez que a Editora Globo fazia publicidade dos lançamentos de obras nacionais e estrangeiras através da RG. Além da Livraria do Globo, na década de 1940, existiam em Porto Alegre outras dez livrarias, das quais sobressaíam a Livraria Selbach e a Livraria Continente. A Livraria Krahe anunciou a mais criteriosa coleção de romances para moças, escritos por M. Delly, Eleanor Porter, Henri Ardel e outros, que poderiam ser adquiridos até pelo Serviço de Reembolso Postal. abr. 1930

11. Ibid. 
a Melhoramentos. É interessante observar que a publicidade de livros feita pela RG é dirigida ao leitor do sexo masculino, que, a pedido da mulher, adquiria a obra. Enquanto o centro do País priorizava os romances, a Editora Globo já editava livros de Huxley, Norman Douglas, Virginia Woolf, Sinclair Lewis e alguns franceses.

Os gaúchos já contavam com sociedades recreativas e esportivas, como o Clube do Comércio, Country Clube, Petrópole Tênis Clube e Sogipa, seguidas dos Gondoleiros e Leopoldina Juvenil. O antigo Teatro São Pedro anunciava suas peças, bem como o Cine Teatro Variedades oferecia espetáculos rigorosamente familiares. Os cinemas Imperial, Guarany, Central, Apollo, Ypiranga, Vera Cruz, Rio, Rex e Roxy movimentavam a noite com projeção de filmes constantemente anunciados pela RG.

Gênero - Matéria-prima: anúncios de produtos não-manufaturados. Neste campo aparecem produtos e serviços usados para confeccionar artigos diversos como lãs, tecidos, madeira, cordões, com 291 veiculações, sendo 86 inéditas. Como a mulher realizava todas as tarefas da casa e, além disso, costurava, bordava, fazia tricô, crochê etc., a publicidade divulgava literatura sobre trabalhos manuais e anúncios de empresas que vendiam tais produtos. Os estabelecimentos comerciais eram Casa Reingantz, anunciante por mais de vinte anos; Casas Brasileiras das Sedas, por cinco anos e oito meses; Lanifício São Pedro, por nove anos e Casas Pernambucanas, considerada a maior empresa têxtil da América do Sul. Os anúncios do Linho Irlandês aparecem em formatos coloridos e de página inteira por mais de três anos.

Gênero - Transporte: anúncios sobre diferentes meios de transporte, num total de 664, sendo 233 inéditos, vendendo navios, automóveis, bicicletas, bem como anunciando transporte de cargas e viagens de avião. Um anúncio publicado na página 38, de 25 de janeiro de 1930, indica que havia viagens de avião para o Rio Grande do Sul e Rio de Janeiro, de vapores para Pelotas, Rio Grande do Sul, Santos e Rio de Janeiro, e de trem para Santa Maria. A cidade possuía serviço de bondes elétricos, explorados pela Cia. Carris Porto-alegrense, e de ônibus, dirigido pelo Sindicato dos Rodoviários. Aparecem, também, as empresas de navegação aérea Panair do Brasil, Viação Aérea Santos Dumont S.A. e Varig, bem como as empresas de navegação marítima Lloyd Brasileiro, Nacional de Navegação, Lloyd Nacional e Carlos Lubisco, todas anunciantes da RG. O Lloyd Brasileiro já oferecia, em 1929, passagens gratuitas a jornalistas uruguaios e argentinos, com o fim de propagar o turismo brasileiro, considerado fonte de grande renda para o comércio e as indústrias ${ }^{12}$. A empresa Exprinter já anunciava na revista, em 1931, viagens de núpcias, organizadas e planejadas com os noivos.

Gênero - Vestuário: oferta de artigos do vestuário masculino e feminino, bem como peças de armarinho e serviços relacionados à confecção de roupas. Neste campo foram catalogados 1.244 anúncios, sendo 421 inéditos, de grandes magazines que vendiam a moda e as novidades trazidas pelos

12. Ibid., n. 19 , p. 72,12 , out. 1929. 
vapores europeus, e que eram ditadas, no início do século, por Portugal, que mandava os corpetes, as capotas de vidrilho, as rendas vindas dos Açores, assim como pela Grécia, com seus bordados delicados etc.

Os homens mandavam fazer seus ternos na Alfaiataria Soares ou eram clientes da Alfaiataria Poli, que com sua tesoura mágica, por mais de cinco anos, propagou que vestia com elegância os cavalheiros da cidade. A Camisaria Rio Branco, integrando-se ao progresso, dotou a cidade de um estabelecimento moderno e elegante, na altura dos seus merecimentos, e foi anunciante da revista por quatorze anos e onze meses.

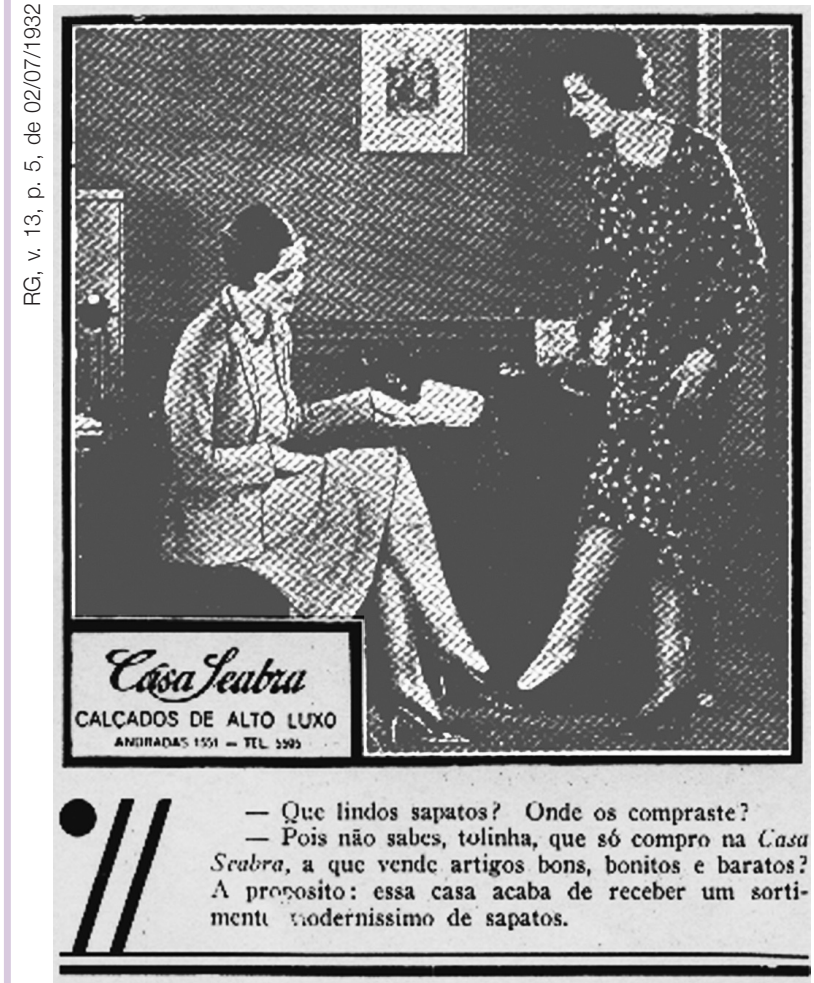

de litro de água florida, bem como tudo o que a mulher elegante da capital pudesse desejar para sua vaidade.

\section{ASPECTOS CONCLUSIVOS}

A matéria armazenada nos primeiros vinte anos da publicidade gaúcha revelou aspectos pouco explorados da história do País, que podem ser trabalhados em sala de aula, produzindo novas versões dos fatos, compartilhando as informações com outras disciplinas, interpretando o passado como uma relação intrínseca entre o produto e o consumidor, dando-lhe coerência interna, sentido e perspectiva ${ }^{13}$. O catálogo já se constituiu em um banco de dados para a elaboração de trabalhos acadêmicos, em várias escolas, universidades e centros de pesquisa, agindo como semente de novos e importantes projetos, finalidade transcendente deste estudo.

de acordo com o mostruário das lojas, e quem não tinha dinheiro para comprar o guarda-roupa da moda, copiava os modelos vindos de Paris e reproduzidos por modistas que anunciavam seus serviços pela RG. Anúncios da Casa Seabra, que vendia sapatos femininos, feitos à mão, foram veiculados por dezesseis anos e quatro meses; a Casa dos Chapéus anunciou por três anos e A Moda, por mais de oito anos. Uma loja que também marcou época foi a Ribeiro \& Irmãos, onde se expunham saias-balão, enchimentos para cabelo, meias, garrafas
13. POMBO, Olga. A interdisciplinaridade: reflexão e experiência. Lisboa: Texto, 1993. 
Para isso, é imprescindível um conhecimento do modo de organização e análise da própria informação nas fontes em que são registradas. Como nem sempre tais atividades fazem parte da experiência imediata do aluno nas escolas, o professor pode coletar documentos, jornais, fotografias, anúncios, filmes e depoimentos de pessoas que viveram outras épocas, construindo um espaço de tempo que utilizava formas simbólicas diferentes da cultura atual, pois "o conhecimento é transitório, está sempre em processo de construção e reconstrução de modo semelhante ao desenvolvimento da inteligência humana, o que refuta a ideia de verdade absoluta e final"14.

Esses fatos vão estar relacionados com a prática, com a capacidade de lidar com a complexidade do dia-a-dia, discutindo as situações que se apresentam em um anúncio do início do século, para refletir sobre como as pessoas viviam nessa época, como substituíam um produto recém-lançado no mercado, que tipo de linguagem era usada pela publicidade para convencer as pessoas da sua necessidade, que mudança trouxe para a coletividade etc., desconstruindo as certezas absolutas e estabelecendo conexões com os símbolos e imagens que estavam sendo construídas em uma nova sociedade.

Isso mostra que o mesmo anúncio busca convir com vários públicos $\mathrm{e}$ a cada um deve ser insubstituível como instrumento de informação, educação e cultura, pois se torna portador de uma mensagem complexa que é preciso aprender a decifrar.

Somente assim tais documentos apresentarão um lado de permanência e outro de produtividade, à espera de quem com eles entre em contato, pois, ao associarem memória e presença, proporcionarão trabalhos inovadores, revisarão noções preconceituosas, permitindo um novo olhar sobre a história. Como diz Castro, "os textos apresentam, assim, situações compartilhadas pelo imaginário da época, revelando em parte a vida cotidiana e em parte o mundo ficcional em que o fluxo dos acontecimentos aparece retratado nos reclames" 15 .

Nesse sentido, a inter-relação entre o investigador e o investigado não pode ser pensada separadamente, pois o que existe no mundo social e humano, em determinada época, é o que se busca nos documentos de um acervo. A resposta metodológica não está apenas nos dados catalogados, nem nas ferramentas utilizadas, mas na estratégia global que orienta e permeia novos trabalhos, dando-lhes coerência interna e novas perspectivas. Especialmente na universidade, a formação profissional precisa ser também uma formação cultural, baseada na comunicação social do conhecimento e na reflexão humana como construtora da história em que a educação e a publicidade aparecem como componentes inseparáveis e complementares de um mesmo processo. Nesta perspectiva, a arte, a história, a comunicação, a educação e outros saberes não serão discutidos, apenas, como produções humanas, mas como explicações dos modos diferenciados de se viver em sociedade, para melhor compreendê-la e transformá-la mediante um agir consciente e crítico.
14. MORAES, Maria Cândida. O paradigma emergente. Campinas: Papirus, 1997.

15. CASTRO, Maria Helena S. de. O literário como sedução: a publicidade na Revista do Globo. Porto Alegre: EDIPUCRS, 2004. 

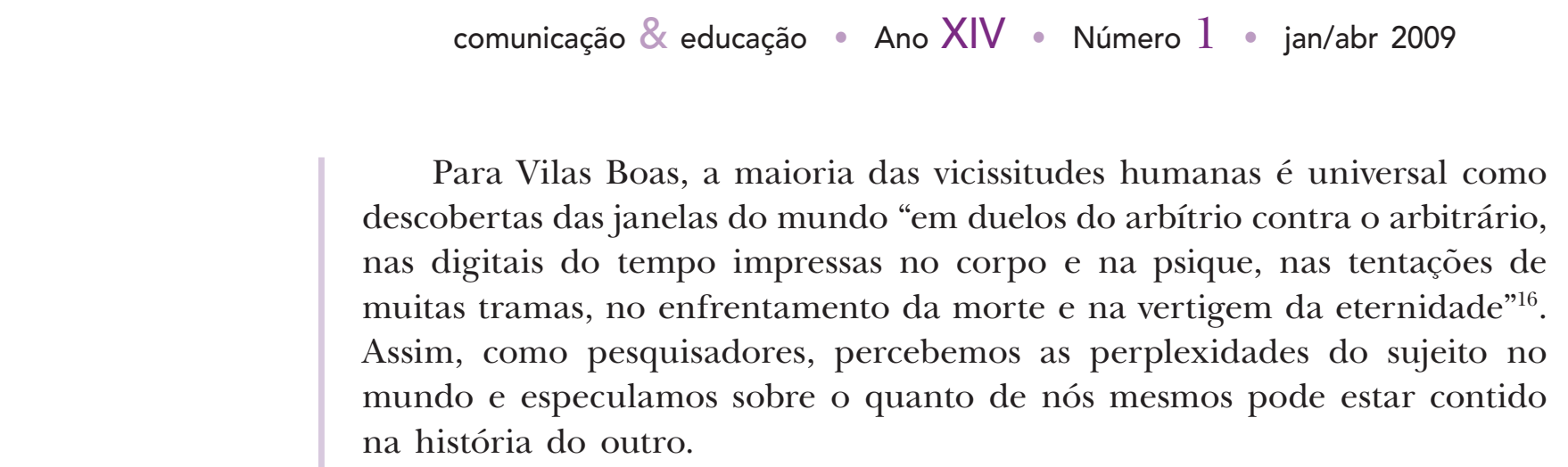

\section{REFERÊNCIAS BIBLIOGRÁFICAS}

BECKER, Fernando. Modelos pedagógicos e modelos epistemológicos. Educação e realidade. Petrópolis: Vozes, 1993.

CASTRO, Maria Helena S. de. O literário como sedução: a publicidade na Revista do Globo. Porto Alegre: EDIPUCRS, 2004.

COBRA, Marcos. O impacto da propaganda: um estudo para algumas classes de bens. São Paulo: Atlas, 1991.

GOMES, Angel Perez. O pensamento prático do professor: a formação do professor como profissional reflexivo. In: NÓVOA, Antonio. Os problemas e sua formação. Lisboa: Dom Quixote, 1992.

MORAES, Maria Cândida. O paradigma emergente. Campinas: Papirus, 1997.

MORIN, Edgar. O método IV - as ideias. Portugal: Europa-América, 1991.

PEREZ, J. T. (Org.). Porto Alegre por dentro e por fora. Visão Panorâmica da capital do Estado do Rio Grande do Sul: sua vida e potencial econômico; retrato da cidade de Porto Alegre. Porto Alegre: Continente, s.d.

POMBO, Olga. A interdisciplinaridade: reflexão e experiência. Lisboa: Texto, 1993.

REVISTA DO GLOBO, Porto Alegre: Livraria do Globo, n. 174, 25 dez. 1935.

, Porto Alegre: Livraria do Globo, n. 19, 12 out. 1929.

, Porto Alegre: Livraria do Globo, n. 32, 26 abr. 1930.

, Porto Alegre: Livraria do Globo, n. 105, 18 fev. 1933.

, Porto Alegre: Livraria do Globo, n. 285, 30 nov. 1940.

VILAS BOAS, Sérgio. Biografias \& biógrafos: jornalismo sobre personagens. São Paulo: Summus, 2002.

16. VILAS BOAS, Sérgio Biografias \& biógrafos: jornalismo sobre personagens. São Paulo: Summus, 2002. p. 170. 